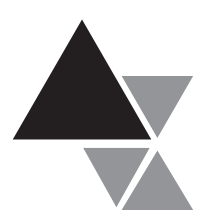

\title{
DINÂMICA TECNOLÓGICA DA CADEIA INDUSTRIAL DA AVICULTURA ALTERNATIVA: MULTIFUNCIONALIDADE, DESENVOLVIMENTO TERRITORIAL E SUSTENTABILIDADE
}

\author{
Luiz Carlos Demattê Filhoํㄹ Paulo Eduardo Moruzzi Marques²
}

\begin{abstract}
Trata o presente artigo de uma proposta de metodologia de pesquisa que busca discutir os referenciais teóricos da multifuncionalidade da agricultura a fim de analisar notadamente um sistema agroalimentar fundado em princípios e métodos da Agricultura Natural. Este sistema se organiza em torno de uma agroindústria integrando produtores locais para oferecer principalmente frangos e ovos. A Agricultura Natural é um modelo produtivo preconizado por Mokiti Okada (Japão, 1882-1955), o qual enfatiza a necessidade de um perfeito equilíbrio entre as atividades humanas e as forças da natureza, para se alcançar bons resultados na produção, privilegiando a segurança dos alimentos, práticas conservacionistas da natureza, a saúde, e o bem-estar socioeconômico de produtores e consumidores. A partir da década de 1990, podemos perceber um incremento das discussões sobre a multifuncionalidade da agricultura devido aos inúmeros problemas sociais e ambientais advindos do modelo agrícola produtivista. Neste mesmo período intensificaram-se os problemas concernentes à segurança alimentar, com os casos da Encefalopatia Espongiforme Bovina (doença da vaca louca), alimentos contaminados com dioxinas e com resíduos de agrotóxicos, emergência de doença zoonóticas como a Influenza Aviária, etc. A ideia então é de discutir em que medida a Agricultura Natural, representando uma inovação tecnológica na produção de alimentos no Brasil e no mundo, oferece bases pertinentes na busca de um modelo agrícola sustentável, em respeito à humanidade e sua diversidade sociocultural e ao meio ambiente. Finalmente, analisamos a pertinência de posicionar o processo produtivo da avicultura alternativa com os referenciais teóricos do Sistema Agroalimentar Localizado (SIAL).
\end{abstract}

Palavras-chave: avicultura alternativa, avicultura orgânica, multifuncionalidade da agricultura, desenvolvimento territorial, sustentabilidade, sistema agroalimentar localizado.

\section{TECHNOLOGICAL DYNAMICS IN THE INDUSTRIAL CHAIN OF ALTERNATIVE POULTRY PRODUCTION: MULTIFUNCTIONALITY, TERRITORIAL DEVELOPMENT AND SUSTAINABILITY}

This article is a proposal for a research methodology that attempts to discuss the theoretical framework of multifunctionality of agriculture in order to analyze an Agrifood System based on the principles and methods of Natural Farming. This system is organized around an agro industrial company which integrates local farmers to produce mainly broilers and eggs. The Natural Farming is an agricultural method advocated by Mokichi Okada (Japan, 1882-1955), which emphasizes the need of a perfect balance between human activities and nature

\footnotetext{
${ }^{1}$ Doutorando do Programa de Pós Graduação Interunidades em Ecologia Aplicada, Escola Superior de Agricultura Luiz de Queiroz/Centro de Energia Nuclear na Agricultura (ESALQ-CENA), Universidade de São Paulo (USP), Campus Piracicaba, SP. Correspondência: Caixa Postal 41 CEP 13537-000 Ipeúna, SP. E-mail: luiz.dematte@korin.com.br

${ }^{2}$ Professor do Departamento de Economia, Administração e Sociologia da ESALQ e do Programa de Pós-Graduação Interunidades (ESALQ-CENA), USP, Campus Piracicaba, SP.
} 
forces, to achieve good results in the production, focusing on food safety, environmental sustainability, health, and socioeconomic welfare of farmers and consumers. Since the 1990's, it has been noticed an increase in the discussions of agricultural multifunctionality due to the numerous social and environmental problems arising from the conventional agricultural model. In the same period, problems concerning food safety have increased, such as the Bovine Spongiform Encephalopathy (mad cow disease), dioxin-contaminated food and pesticide residues, and the emergence of animal and human diseases as the Avian Influenza. Natural Farming as a method may represent an important technological innovation in food production in Brazil and around the world, and offer a solid contribution in the quest for a sustainable agricultural model, respecting mankind, their socio-cultural diversity and the environment. Finally, the relevance of situating the productive process of an alternative aviculture with the theoretical framework of the Localized Agrifood System- LAS is analyzed.

Key-words: Sustainability, natural farming, organic broilers, rural development, multifunctionality of agriculture, localized agrifood systems.

\section{INTRODUÇÃO}

Os avanços na avicultura industrial vêm ocorrendo através de processos produtivos intensivos. No período de 2002 a 2010, a produção mundial de frango aumentou em 22,66\% e de 2001 a 2008, a produção de ovos elevou-se em $14,73 \%$. No período de 2005 a 2010 a produção brasileira de carne de frango elevou-se em 24,07\%, atingindo em 2010 a impressionante quantidade de 12.312.200 toneladas, posicionando o Brasil entre os três maiores produtores de carne de frango e o principal país exportador no cenário mundial ${ }^{[1]}$. A recente e rápida expansão da produção de alimentos de origem animal contribuiu para o aumento da concentração de animais, nos estabelecimentos agropecuários, e pessoas, nas maiores cidades dos países em desenvolvimento, conduzindo ao aumento na incidência de doenças zoonóticas, como salmonelose e influenza aviária, além da presença de microrganismos patogênicos nos produtos, como E. coli. A intensificação da produção animal vem motivando em muitas partes do mundo o aumento da ocorrência de pesticidas e antibióticos na cadeia alimentar ${ }^{[2]}$.

Outra consequência decorrente da intensificação da produção foi o aumento do uso dos aditivos antimicrobianos na alimentação animal, cujos riscos potenciais incluem desde reações de hipersensibilidade até propriedades cancerígenas. Esses produtos passaram a ser vistos como fatores de risco para a saúde humana e sua aplicação passou a ser contestada, principalmente quanto à presença de resíduos na carne, ovos ou leite, que podem ser os próprios aditivos ou seus metabólitos acumulados nos produtos comestíveis e também quanto à indução de resistência cruzada de bactérias patogênicas para humanos ${ }^{[3]}$.

Uma parte significativa da população brasileira já valoriza alimentos produzidos por processos fundados em valores sociais e ambientais sustentáveis. Embora exista uma enorme demanda por produtos de baixo custo, cresce também a demanda por qualidade. Neste caso, é preciso garantir atributos específicos como ausência de resíduos agrotóxicos ou antibióticos. Além disso, o bem-estar dos animais de produção também passou a ser um ponto de atenção dos consumidores. Assim, as exigências destes últimos motivaram o estabelecimento de legislações regulamentadoras e normas técnicas com o objetivo de garantir a oferta de produtos seguros.

Nestas circunstâncias, este artigo discute características de sistemas de produção alternativos e aponta para perspectivas de análise pertinentes para o estudo de seus impactos territoriais.

\section{SISTEMAS ALTERNATIVOS DE PRODUÇÃO}

Aspectos sobre a segurança do alimento despertam a atenção da população, principalmente porque há uma grande assimetria de informação entre o consumidor e o produtor de alimentos. Geralmente, o consumidor tem informações incompletas sobre os procedimentos efetuados durante o processo de produção e não tem como saber, a um baixo custo, sobre características intrínsecas como a existência de resíduos de antibióticos e promotores de crescimento ${ }^{[4]}$. Porém, a emergência de novas referências de qualidade alimentar vem favorecendo 
o desenvolvimento de soluções inovadoras, tais como as certificações de conformidade: selo orgânico, selo de comércio justo Fair Trade, selo de bem-estar animal e o selo GlobalGAP, são exemplos. Trata-se de permitir o reconhecimento de práticas mais zelosas com o meio ambiente, com os animais de produção e com a saúde do consumidor e da população rural.

A partir da década de 1990, algumas empresas passaram a pesquisar alternativas para alimentar as aves com ingredientes mais naturais e saudáveis. Surgiram no Brasil, iniciativas de produção de frangos criados "sem antibióticos terapêuticos, sem antibióticos como melhoradores de desempenho" e "sem ingredientes de origem animal na ração". A criação alternativa de frangos surgiu como opção ao consumidor ${ }^{[5]}$.

Isto parece ter emergido como uma consequência por demandas mais sustentáveis na produção de alimentos, ao mesmo tempo em que se intensificaram os debates sobre o papel da agricultura devido aos problemas fundiários, aos impactos ambientais e à crônica escassez de recursos financeiros, notadamente no que se refere aos agricultores, sobretudo os pequenos e médios.

No Brasil, a primeira referência a esse respeito aconteceu durante a Conferência Rio-92, onde se adotou a discussão do desenvolvimento sustentável no âmbito da agricultura e do meio rural, fundamentando as críticas às consequências econômicas, sociais e ambientais da chamada Revolução Verde ${ }^{[6]}$. Este debate está presente igualmente em torno da função social da propriedade rural, tal como pode ser interpretada no artigo 186 na Constituição brasileira ${ }^{[7]}$.

A União Europeia está propondo a um grupo restrito de países, entre os quais figura o Brasil, a inserção das regras de bem-estar animal nas normas da Organização Mundial do Comércio (OMC). Algumas redes varejistas da Europa já começaram, por exemplo, a vender apenas ovos de aves criadas em sistema com amplas áreas livres para pastejo. Até 2012, serão proibidas criações em certas instalações industriais. Desde 2003, nenhum novo projeto de avicultura recebe autorização sem esse planejamento ${ }^{[8]}$. Essas regras, associadas às exigências do mercado consumidor, estimulam o desenvolvimento de processos produtivos voltados também para o equilíbrio sanitário e redução da dependência de medicamentos.
No Brasil, leis e regulamentações vêm sendo estabelecidas nesse sentido. Na Lei no 10.831, de 23/12/2003, a proteção do meio ambiente e a responsabilidade social são componentes do sistema orgânico de produção [?]. Os produtos orgânicos atraem a atenção dos consumidores, pois além das qualidades intrínsecas, decorrentes do sistema de produção, possuem qualidades extrínsecas, como: a) proteção do meio ambiente, possibilitada pelo desenvolvimento de um sistema produtivo sustentável; e b) coesão social, pois esse sistema exige uma utilização maior de mão de obra, sendo uma boa alternativa para o pequeno estabelecimento familiar. Neste ponto, convém lembrar que o alimento orgânico favorece o reconhecimento dos cuidados com o produto e com o território de produção, o que repercute sobre a autoestima dos agricultores. Tais aspectos têm motivado o consumo crescente dos alimentos orgânicos, principalmente na Europa ${ }^{[4]}$.

No Brasil também existe a tendência do consumidor valorizar o alimento orgânico. Essa constatação tem sido detectada em várias pesquisas de mercado. Nos últimos anos, grandes varejistas como Pão de Açúcar e Carrefour vêm ampliando a oferta de produtos orgânicos, com apelos à vida saudável (destinando estes alimentos a consumidores de alto poder aquisitivo). Convém lembrar que esta tendência tem base em uma percepção subjetiva do consumidor a respeito de tais produtos. Inevitavelmente a formação de preço de produtos orgânicos é um complicador para sua maior difusão. Há um grande diferencial de preços que podem variar de 20 a $200 \%$ mais caros quando comparados aos mesmos produtos convencionais e parte desse prêmio no preço é resultado das diferenças nos custos de produção e de distribuição ${ }^{[10]}$.

Mais recentemente amplia-se a discussão sobre métodos diferenciados de produção de frangos e ovos. Há grandes brechas na legislação brasileira a respeito destes métodos. Um exemplo claro consiste na ausência de normas específicas para a produção dos frangos e ovos caipiras, mesmo sendo algo inerente à cultura rural brasileira e perfeitamente reconhecida pela imensa maioria da população do país.

Neste ponto é inevitável a comparação com a França, visto que lá métodos diferenciados de produção de aves foram estudados com ênfase e normatizados pelo setor público, constituindo- 
se em importantes oportunidades de trabalho para a população rural. A propósito, esta produção representa volumes significativos da oferta de carne de frangos e ovos em todo o país. A carne de frangos com certificação Label Rouge representa $25 \%$ de todo o frango produzido e consumido no país ${ }^{[11]}$. O selo Label Rouge é um selo oficial do Ministério da Agricultura Francês concedido aos produtores que atendam os requisitos de conformidade à qualidade diferenciada destes produtos, os quais são descritos em protocolos específicos e, portanto, passíveis de auditorias regulares, conferindo credibilidade aos processos e produtos dele advindos. Os produtos, por si só, transformam-se em excelentes meios de comunicação junto aos seus consumidores, eminentemente urbanos, ampliando o conhecimento e a conscientização dos mesmos acerca da necessidade de prover a sustentação da produção agrícola integrada a um desenvolvimento rural sustentável.

\section{O INTERESSE PELAS AGRICULTURAS EMERGENTES}

No contexto internacional marcado pelo retorno da agricultura na agenda das políticas públicas e pelo avanço considerável das problemáticas de desenvolvimento sustentável, as "agriculturas emergentes" passam a ser objeto do interesse social e, por consequência, da atenção dos pesquisadores em ciências sociais. No Brasil e na França observase, com efeito, uma multiplicação de iniciativas que contribuem a uma reorganização das práticas e dos sistemas de atividades agrícolas segundo modelos mais ou menos em ruptura com aqueles da agricultura produtivista. Nascendo de iniciativas localizadas ou encorajadas por redes com ramificações nacionais e internacionais, estas práticas agrícolas emergentes constituem um leque de alternativas que poderiam se revelar promissoras no âmbito dos paradigmas do desenvolvimento agrícola territorializado e do desenvolvimento sustentável.

Este fenômeno levou pesquisadores brasileiros e franceses a elaborar um projeto de cooperação a fim de identificar e caracterizar (sob uma abordagem interdisciplinar que toma em conta as dimensões sociais, econômicas e ambientais) os perfis e trajetórias destas "agriculturas emergentes" e situá-las em relação a modelos tais como aquele da agricultura familiar ou dos sistemas agroalimentares localizados. Trata-se igualmente de analisar as relações que elas desenvolvem com as formas de agricultura convencional, assim como, os elos que constroem com o território. Desta forma, a intenção desta cooperação consiste notadamente em construir referenciais analíticos para o estudo destes sistemas emergentes.

Neste âmbito, é sabido que a agricultura orgânica aproxima-se em muito das ideias acerca do papel multifuncional da atividade agrícola e é reconhecida como próxima aos movimentos que buscam priorizar a agricultura familiar como um modelo capaz de prover a sustentação do homem no campo. Algumas destas correntes, nascidas justamente de movimentos contrários aos métodos agrícolas convencionais, somente ganharam espaço no Brasil após a consolidação do processo de "modernização da agricultura", na medida em que os resultados negativos desse modelo foram identificados e disseminados pela sociedade. Pesquisas mostram que a saúde é o primeiro aspecto enfatizado pelos consumidores quando questionados sobre a motivação para a compra de produtos orgânicos ${ }^{[2]}$. A proteção ambiental que a produção orgânica promove é ainda pouca conhecida pelos consumidores em geral, sendo, no entanto, mais enfatizada junto aos consumidores habituais desses produtos.

Os principais modelos ou correntes de agricultura não convencional que ocorrem no país são: a Agricultura Natural, Agricultura Biodinâmica, a Agroecologia e a própria Agricultura Orgânica. Esta ultima foi legalizada no país pela Lei 10.831, de 23 de Dezembro de 2003, e pelo Decreto 6.323, de 27 de Dezembro de 2007. Na sequência foi regulamentada por instruções normativas (INs) do Ministério da Agricultura, Pecuária e Abastecimento (MAPA). A IN 46, de 07 de Outubro de 2011, substitui e aprimora a anterior (IN 64) e é um ponto central neste processo, pois normaliza os sistemas orgânicos de produção animal e vegetal. Uma série de outras INs foram editadas e publicadas regulamentando o sistema mais detalhadamente, sendo que as mais recentes são IN conjuntas entre o MAPA, Ministério do Desenvolvimento Agrário (MDA) e Ministério do Meio Ambiente (MMA), demonstrando o caráter multifuncional e interinstitucional do sistema.

As diferentes denominações acima descritas, as quais preservam certas características técnicas e 
filosóficas distintas foram agrupadas com o nome de Agricultura Orgânica ${ }^{[13]}$. Assim, todos os produtos que chegam ao consumidor, produzidos no campo das diversas agriculturas não convencionais, são rotulados e denominados como produtos orgânicos, desde que atendam também seus requisitos mínimos de produção.

Um produto oriundo de um manejo agroecológico, não necessariamente será um produto orgânico e tampouco poderá ser comercializado como tal, a menos que todos os requisitos de certificação para o sistema orgânico sejam cumpridos. Compreende-se assim, que o sistema orgânico se volta ao mercado, destinado a ofertar produtos certificados que como tal ostentem o selo do Sistema Brasileiro de Avaliação da Conformidade Orgânica (SISORG).

Neste ponto, discorrendo mais especificamente sobre a Agricultura Natural, é possível destacar que o método foi desenvolvido colocando a questão da saúde humana como um objetivo central. Desta forma, a propagação e desenvolvimento da produção de aves e ovos no Brasil, cuja grande produção é fundada em sistema industrial intensivo, intensificação e uso recorrente de medicamentos (particularmente antibióticos para controlar não só os problemas sanitários, mas também promover a melhoria nos índices de produtividade), levam a dúvidas e questionamentos sobre a qualidade destes produtos alimentares. Nestas circunstâncias, a Agricultura Natural, com sua produção de frangos e ovos em sistemas alternativos, isentos de antibióticos, promotores de crescimento e demais medicamentos, passa a ter um reconhecimento enquanto padrão emergente de qualidade. Assim, a agricultura natural é tomada como representativa dos frutos das críticas contra a agricultura convencional e como alternativa emergente no âmbito do projeto de cooperação mencionado acima.

\section{A AGRICULTURA NATURAL E A PRODUÇÃO AVÍCOLA}

O modelo da Agricultura Natural se baseia nos escritos e orientações deixados por Mokiti Okada (1882-1955), filósofo e espiritualista japonês que elaborou um extenso trabalho abordando assuntos ligados à política, economia, educação, moral, arte, medicina, religião e agricultura. Esta última é considerada como um dos pilares de sustentação da criação de uma nova civilização. Mokiti Okada denominou este modelo de produção agrícola como Agricultura Natural, destacando que sua finalidade reside na responsabilidade total pelo abastecimento de alimentos, que são os alicerces para se construir um mundo ideal, isento da doença, da pobreza e do conflito. E ainda, reside na observância das leis fundamentais da sobrevivência, alicerçadas na correta visão sobre a natureza, estabelecendo-se um modelo de produção sustentável ${ }^{[14]}$.

Convém desde já destacar que, apesar do modelo da Agricultura Natural ter sido escrito e inicialmente realizado no Japão, foi no Brasil que encontrou um campo fértil para seu desenvolvimento. Seu crescimento em território brasileiro é maior do que em qualquer outro país.

Realçando esta importância brasileira neste campo, convém assinalar que o princípio fundamental da Agricultura Natural é o absoluto respeito à natureza, concebida como grande mestra ${ }^{[15]}$. O modelo possui uma base teórica que privilegia a saúde humana, responsabilidade social, preservação do meio ambiente e práticas de produção mais naturais, respondendo às expectativas de um número crescente de pessoas em todo mundo. De tal modo é possível destacar ideias como: "quando se observa o desenvolvimento e o crescimento de tudo que existe, compreende-se que não há nada que não dependa da força da Grande Natureza" ${ }^{[16]}$. Portanto, esta perspectiva propõe que se devam observar os processos naturais e introduzilos naqueles de produção de alimentos. Pelos escritos deixados por Mokiti Okada ${ }^{[15]}$ podemos observar uma acentuada preocupação com o bem-estar do produtor, com a preservação do meio ambiente, notadamente com a fertilidade do solo, alcançada exclusivamente por práticas naturais.

Mokiti Okada enfatiza ainda em seus trabalhos a necessidade de que os agricultores despertem para sua elevada missão que é a de produzir alimentos nobres e puros voltados ao desenvolvimento físico, mental e emocional de homens e mulheres, capacitando-os a construir um mundo onde predomina a saúde, a paz e a prosperidade. A disseminação desta compreensão entre consumidores torná-los-ia atores num processo de construção de condições ideais no ambiente rural. A simples compra de gêneros alimentícios desta natureza transforma-se assim num processo 
consciente de consumo, onde o valor agregado nos produtos transfere-se a montante, beneficiando seus produtores primários.

Aqui, convém mencionar que MoruzziMarques \& Miguel Silveira ${ }^{[17]}$ analisam um fenômeno pertinente de adoção de uma postura favorável à gestão sustentável das propriedades rurais que consiste, em grandes linhas, em reforçar a agricultura familiar, respeitar a natureza, assegurar a qualidade alimentar e permitir uma dinamização territorial. De fato, trabalhos recentes de pesquisadores brasileiros revelam o interesse acadêmico crescente por princípios existentes no âmbito da Agricultura Natural.

Na medida em que o método da Agricultura Natural foi ganhando adeptos no ambiente agrícola, meios comerciais tiveram que ser executados para permitir o escoamento de produtos. Desta forma, uma escala comercial se desenvolveu permitindo o desenvolvimento e a produção de frangos e ovos diferenciados. Concorrentemente, aconteceu um amplo desenvolvimento tecnológico, o qual permitiu a produção em bases sanitárias e econômicas sustentáveis, verificadas na melhoria do rendimento e qualidade dos produtos do abatedouro, nas granjas avícolas integradas de frango e ovos, na fábrica de ração e, sobretudo na fidelização dos produtores a este método em detrimento do método convencional oferecido por um grande número de empresas integradoras de frangos.

Também vale lembrar aqui que a pesquisa em cooperação franco-brasileira em torno das agriculturas emergentes se inspira, em grande medida, nos trabalhos sobre a multifuncionalidade da agricultura. Neste âmbito, pesquisadores brasileiros e franceses em projetos conjuntos privilegiaram quatro principais funções associadas ao exercício da atividade agrícola: a reprodução socioeconômica das famílias rurais; a promoção da segurança alimentar das próprias famílias e da sociedade; a manutenção do tecido social e cultural e a preservação dos recursos naturais e da paisagem rural ${ }^{[6]}$.

Nossos estudos sobre a atividade avícola diferenciada permitirão discutir suas contribuições para tais funções, tais como a melhor remuneração do produtor contribuindo para a fixação de sua família no campo, o fortalecimento do tecido social rural, o aumento da diversidade territorial, e por fim, a melhoria da qualidade alimentar e da saúde de produtores e consumidores.

Ainda cabe lembrar outro aspecto fundamental em torno da grande rede de suprimentos que os modelos produtivos necessitam para funcionar adequadamente. $\mathrm{Na}$ produção de aves é imprescindível a oferta constante e com qualidade de alimentação animal. Assim, a avicultura natural estimula a constituição de uma significativa rede de produção destes insumos, pautadas igualmente pelos princípios da Agricultura Natural, iniciando com a redução do uso de adubos solúveis e agroquímicos e com o uso de compostos naturais nas áreas integradas de produção de grãos para a obtenção de colheitas igualmente produtivas.

\section{OS ASPECTOS INOVATIVOS DA PRODUÇÃO}

Existem empresas brasileiras de produtos naturais e orgânicos, produzindo desde FLVC (frutas, legumes, verduras e cereais) exclusivamente orgânicos e certificados, até ovos e carne de frango em sistemas alternativo e também orgânico. Tais empresas exercem uma grande influência regional no seu ambiente de produção rural e contribui com a elevação da consciência de milhares de pessoas em todo o Brasil para as questões sociais, ambientais e de saúde concernentes à produção de alimentos.

Para estas empresas, a certificação, por instituições independentes, pode ser um instrumento para a sustentação da sua marca. A certificação transmite para o consumidor informações não perceptíveis, como o processo de produção, ao mesmo tempo em que pode evitar a entrada de oportunistas ${ }^{[18]}$.

Quanto à comercialização, a pequena escala é compensada pela estratégia de diferenciação de produto. Esta exige que o atributo diferenciador seja garantido pela empresa e que o mesmo seja percebido e valorizado pelo consumidor. Farina \& Almeida $2002{ }^{[19]}$, em estudo exploratório da percepção dos consumidores de frango alternativo, verificaram que apesar das características dos produtos serem de difícil observação, o diferencial de preço sinaliza que os consumidores valorizam alguns atributos do frango natural que não estão presentes no convencional. Esses consumidores fazem parte das classes $\mathrm{A}$ e B, tanto em termos de renda quanto em termos de escolaridade. 
Esta crescente demanda permite apontar a importância de estudos sobre a cadeia avícola diferenciada, como a avicultura natural, uma vez que, nos últimos anos, poucos foram os trabalhos desenvolvidos relativos a modelos de produção avícola de corte e postura, sem a utilização de medicamentos e insumos químicos industriais. De fato, muitas das orientações que sustentam sistemas orgânicos e alternativos de produção anteciparam tendências que atualmente expressam-se no mercado global de alimentos. O método da Agricultura Natural não foge a esta condição e parece trazer uma importante contribuição à produção de alimentos desta qualidade. Ressalta-se portanto a escassez de trabalhos acadêmicos mais estruturados, capazes de elucidar ou mesmo apresentar nos campos científico e profissional os diferenciais, a amplitude e os potenciais benefícios deste modelo.

Assim, entre as linhas de questionamentos pertinentes, seria conveniente saber em que medida a implantação de um sistema avícola da Agricultura Natural favorece um desenvolvimento territorial mais equilibrado, promovendo a produção familiar e o cuidado ambiental. Então, uma empresa agropecuária que produz em modelos verticalizados, através da integração dos produtores, e que busca adequar e harmonizar todas as práticas de produção, de forma a ter uma matéria-prima com a garantia de ter sido produzida com os diferenciais do método da Agricultura Natural, poderia contribuir até que ponto para o desenvolvimento rural sustentável?

Podemos considerar aqui que é crescente o reconhecimento de que diferentes formas de organizar a produção têm impactos significativos sobre a capacidade de reação a mudanças no ambiente competitivo, identificação de oportunidades de lucro e ação estratégica ${ }^{[20]}$. Deve-se considerar ainda o desconhecimento dos consumidores sobre os diferenciais dos produtos orgânicos e alternativos, a dificuldade de enquadrar a criação nas normas sanitárias da avicultura industrial, a ausência de regulamentação quanto aos padrões de qualidade dos produtos e as restrições técnicas impostas pelas normas orgânicas de produção, causando um impacto na eficiência e competitividade das empresas neste modelo produtivo.

Por outro lado, num ambiente de concorrência industrial, as cadeias de produção de frangos e ovos podem ser consideradas como um dos setores mais eficientes do país. Isto traz implicações e dificuldades óbvias para qualquer iniciativa que busque a diferenciação. Sabemos que os consumidores em geral, aceitam pagar um prêmio de preço, entretanto, há limites claros nesta liberalidade ${ }^{[19]}$. A diferenciação deverá ser cuidadosa, pois não haverá sustentação do processo da avicultura alternativa se a produtividade e eficiência não forem muito bem consideradas como um dos requisitos necessários (e de constante busca pelo produtor e pela agroindústria), no caso de processos integrados de produção. Caso contrário, a diferença entre os preços de um produto alternativo e do convencional similar se tornará tão elevada que limitará a expansão de um modelo diferenciado.

Especificamente na produção orgânica de frangos, podemos já observar este fenômeno no Brasil. Os requisitos da legislação da produção orgânica são a tal ponto exigentes que, desfavorecendo a eficiência produtiva, tornam o produto final demasiado caro e, portanto, acessível apenas a parcela muito limitada dos consumidores, aprisionando o processo num mercado de nicho. No modelo produtivo orgânico, podem ocorrer problemas significativos, como no suprimento e armazenagem de grãos com certificação orgânica para produção das rações, com diminuição da eficiência produtiva, aumento de custo e prejuízo à qualidade devido a reações de oxidação de gorduras e infestação de pragas, por exemplo. Outro requisito diz respeito à menor densidade de alojamento nos aviários, reduzindo a renda do produtor orgânico.

Custos e produtividade são indicadores de eficiência que explicam em parte a competitividade. No entanto, inovação em produto e processo, para atender adequadamente demandas por atributos específicos de qualidade exigidos por consumidores ou clientes, também explica um desempenho favorável que, se não prescinde de custos e produtividade, pode ser elemento determinante da preservação e melhoria das participações de mercado ${ }^{[21]}$. Nesta linha, o desenvolvimento tecnológico recente vem permitindo que o setor agrícola possa responder à crescente diversidade da demanda, por meio da identificação e separabilidade de atributos valorizados pelo consumidor, tais como conteúdo controlado de gordura, proteína, carboidratos ou ainda, alimentos sem resíduos químicos, etc. ${ }^{[20]}$. 
Deve-se destacar ainda a importância que as economias de escala têm na avicultura em todo o mundo. O crescimento do formato de integração na produção do frango permite a redução dos custos de produção e de transação, resultando no aumento da competitividade, que geralmente se inicia na redução dos preços dos fatores de produção, frango, ração, insumos, etc. ${ }^{[22]} . \mathrm{Na}$ avicultura alternativa, as empresas operam em escalas significativamente reduzidas. Assim, é necessário que desenvolvam inicialmente uma capacidade de encontrar e explorar nichos de mercado, reduzindo o impacto da escala na competitividade do negócio, caracterizando uma estratégia genérica com exploração de nicho ${ }^{[23]}$.

\section{A CADEIA DE PRODUÇÃO DA AVICULTURA ALTERNATIVA}

A análise e compreensão da cadeia produtiva da avicultura natural poderão contribuir para a cooperação entre os agentes, o estabelecimento de políticas públicas e o direcionamento de investimentos, com o aumento da competitividade e crescimento do mercado para produtos brasileiros. Neste sentido, é muito pertinente estudar quais são os impactos sociais, territoriais, ambientais e econômicos da estruturação de um sistema integrado de produção avícola nos moldes da produção natural.

Numa visão sistêmica, comparando-se as várias cadeias produtivas de alimentos no Brasil, talvez possamos perceber que aquelas de produção avícola sejam as mais fortemente orientadas para a produção e para a redução de custos, gerando uma estrutura dominada pelas grandes agroindústrias do setor. Neste modelo, é notória a dificuldade que se tem em distribuir os benefícios marcadamente em direção ao produtor. Há uma acirrada disputa de preços, reduzindo margens, que na maioria das vezes esmaga o pequeno agricultor. Assim uma estratégia de escopo, como no caso da produção diferenciada com atributos específicos de qualidade, pode permitir que o prêmio de preço pago pelo consumidor possa se transmitir à montante, rentabilizando o produtor, favorecendo o desenvolvimento rural sustentável.

Uma cadeia de produção agroindustrial pode seguir um ciclo de vida análogo ao ciclo de vida dos produtos, atingindo uma "fase de declínio" que assinalaria sua substituição por um sistema mais eficiente, tributário de novas tecnologias, bem como de uma nova rede de relações técnicas, logísticas e comerciais ${ }^{[24]}$. Interessa-nos neste caso avaliar a construção de novas redes de relação, sobretudo as relacionadas às questões sociais, culturais e ambientais no meio rural.

O modelo de estudo das cadeias agroindustriais e seu enfoque sistêmico permite-nos utilizá-lo em relação às suas principais aplicações para esta análise. Como uma ferramenta de descrição técnico-científica, análise da estratégia das firmas, das inovações tecnológicas e da competitividade. Neste caso em particular, utilizá-la ainda como subsídio para formulação de políticas públicas, relacionadas às normativas referentes à segurança alimentar, pode ser de especial interesse ${ }^{[25]}$.

É relevante o papel dos consumidores nestes desenvolvimentos. Qual é o impacto das mudanças culturais da sociedade nos processos produtivos e nos modelos de gestão da cadeia? ${ }^{[24]}$. Nesta perspectiva, além dos fatores inerentes à cadeia agroindustrial, como mercado, tecnologia e logística, importam-nos o conhecimento de fatores culturais, sociais e ambientais presentes neste processo, os quais contribuiriam para o desenvolvimento do território.

\section{SISTEMA AGROALIMENTAR E DESENVOLVIMENTO TERRITORIAL}

A avicultura de corte e de postura é um dos setores produtivos mais intensivos onde escala de produção e ganhos de produtividade são fatores de sucesso. No Brasil, o gigantismo da indústria avícola também a expõe junto aos seus próprios consumidores a críticas e dúvidas cada vez mais frequentes sobre a qualidade dos produtos. O uso intensivo de antibióticos e o pouco cuidado com as questões de bem-estar animal em razão notadamente pelo confinamento são objeto de contestações crescentes. Adicionalmente em campos técnicos, acadêmicos e governamentais, discute-se o impacto ambiental provocado pela crescente necessidade da produção intensiva de grãos destinados à alimentação das aves. Por outro lado, as dúvidas sobre os benefícios em termos de qualidade de vida e de melhora socioeconômica de produtores e trabalhadores do setor se ampliam em razão da escala dos investimentos necessários para que as famílias rurais possam permanecer na atividade. Pelo lado da saúde pública, em todo o mundo, discute-se a emergência de bactérias resistentes a antibióticos, a 
contaminação por dioxinas na cadeia de suprimentos, afetando os produtos finais, como no recente caso que acometeu produtores de ovos, frangos e suínos na Alemanha ${ }^{[26]}$, e o crescente risco associado às epidemias zoonóticas.

A própria dinâmica da avicultura industrial brasileira e sua inserção no comércio mundial, resultado da ampliação de sua competitividade, passou a estimular uma reflexão e um debate sobre modelos diferenciados que pudessem representar alternativas produtivas. Tais modelos, fundados em especificidades de seus produtos, podem promover o desenvolvimento local com externalidades positivas no que diz respeito em particular na mobilização e valorização de tipicidades territoriais.

Assim, podemos propor a hipótese que alguns elementos típicos de um Sistema Agroalimentar Localizado (SIAL) são encontrados neste processo produtivo. Desta forma, a abordagem do SIAL nos parece muito adequada para oferecer meios consistentes para uma análise deste tipo.

O território no qual se desenvolve os processos de produção de frangos e ovos no método da agricultura natural, no passado, foi um dos principais pólos de desenvolvimento da avicultura no país. Como tal, contribuiu enormemente para os avanços em produção de frangos e na implantação de empresas cujo principal negócio relacionava-se a comercialização de material genético. Ainda hoje, trata-se de uma região importante no contexto da produção nacional. Num dado momento, no início das atividades da empresa que trabalha sob os princípios da agricultura natural, muitos destes produtores convencionais migraram para este novo modelo. Recebendo treinamentos técnicos, conceituais e filosóficos do método, engajaram-se no processo, inicialmente devido a diferenciais de preço pago, mas, posteriormente, expressando certo grau de fidelização e de apreço pelos diferenciais metodológicos e conceituais desta orientação produtiva. Desta forma, o processo de diferenciação se consolida progressivamente, revelando riquezas e agregação de valores até então não exploradas. Construiu-se assim uma dinâmica de relações não exclusivamente mercantis entre os agentes, além de se evidenciar, ainda mais intensamente, como uma estratégia de adaptação aos limites externos, permitindo aos atores reorganizarem a economia local em face da economia de escala e "comoditização" alcançados pelos produtores e empresas convencionais ${ }^{[27]}$. A propósito, Bernard Pecquer enfatiza a especificidade dos ativos do território como um fator característico de um SIAL. No caso de frangos e ovos produzidos no método natural, as especificações fundamentam o sistema, possuindo, portanto, um custo de irreversibilidade, visto que sua comercialização como um produto genérico só aconteceria mediante significativos prejuízos financeiros e, em consequência, perda de sustentação. Uma questão susceptivel de análise aqui se refere às associações destes produtos a territórios determinados, o que reforça em grande medida suas especificidades.

Nesta linha de raciocínio inspirado na abordagem SIAL, é possível salientar que todo o processo subsiste graças a consumidores dotados de uma preocupação alimentar diferenciada, priorizam a aquisição de alimentos com atributos de diferenciação de qualidade, cujas características foram anteriormente examinadas. Além da especificidade dos consumidores e de sua exigência alimentar, Muchnik, Cañada e Salcido consideram mais duas condições para a persistência destes modelos: especificidade dos homens e mulheres e de suas instituições e especificidade dos produtos e dos processos de qualificação associados ${ }^{[28]}$.

Os selos de certificação associados aos produtos ampliam a exigência de capacitação técnica, operacional e conceitual dos produtores, tornando-os agentes mais capazes e esclarecidos para trabalhar e incrementar a segurança dos métodos e diferenciais empregados, ao mesmo tempo em que alimentam a confiança dos consumidores sobre os produtos que adquirem.

Agentes e ações relacionadas e interdependentes que se retroalimentam reforçam a nosso ver a pertinência do SIAL para o estudo do modelo em questão.

\section{CONCLUSÃO}

Crises econômicas com consequências nos sistemas agroalimentares vêm se repetindo a intervalos bastante curtos, comprometendo o acesso de milhares de pessoas ao alimento. Adicionalmente observase um intenso movimento daqueles que, em níveis socioeconômicos mais elevados, preocupados com a saúde e bem-estar (individual e coletivo) aceitam pagar mais por alimentos de qualidade e com diferenciais produtivos nos aspectos sociais, ambientais, técnicos e éticos da produção. As críticas aos modelos produtivos 
convencionais e aos sistemas globais de distribuição de alimentos se intensificam, abrindo oportunidades para que os referenciais de uma agricultura multifuncional se estabeleçam. Com seu enfoque social e ambiental, além daquele relativo à qualidade alimentar e nutricional, a abordagem multifuncional para a agricultura constitui uma ferramenta útil para estudos aprofundados de dinâmicas produtivas em termos de sua sustentabilidade e de sua contribuição para o desenvolvimento territorial.

A Agricultura Natural, assim como também a Agricultura Orgânica, a Agroecologia e a Agricultura Biodinâmica podem ser avaliadas, portanto, sob a ótica da multifuncionalidade. Trata-se assim de considerar tal abordagem como das mais instigantes para a análise de práticas agrícolas alternativas e de todas as dinâmicas em torno destas modalidades de conceber a agricultura.

\section{REFERÊNCIAS}

1. Anuário de Pecuária Brasileira (ANUALPEC), São Paulo, p. 260, 263, 271, 2011.

2. Delgado C, Rosegrant M, Steinfeld H, Ehui S, Courbois C. Livestock to 2020: The next food revolution. 2020 Vision Discussion Paper no 28. Washington, D.C.: International Food Policy Research Institute; 1999.

3. Menten JFM. Aditivos alternativos na nutrição de aves: probióticos e prebióticos. In: Mattos WRS et al. A produção animal na visão dos brasileiros. Piracicaba: FEALQ; 2001. p. 141-57.

4. Rezende CLA. A coordenação do sistema agroindustrial do tomate orgânico no Estado de São Paulo e o comportamento do consumidor [dissertação]. São Paulo: Faculdade de Ciências Farmacêuticas; Faculdade de Economia, Administração e Contabilidade e Faculdade de Saúde Pública, Universidade de São Paulo; 2003. 94 p.

5. Demattê Filho LC. Aditivos em dietas para frangos de corte criados em sistema alternativo [dissertação]. Botucatu: Faculdade de Medicina Veterinária e Zootecnia, Universidade Estadual Paulista; 2004. 95 p.

6. Carneiro MJ, Maluf RS. Para além da produção: multifuncionalidade e agricultura familiar. Rio de Janeiro: Mauad; 2003.
7. Alles JM, Marques PEM. Debate sobre Funções Sócioambientais da Propriedade Fundiária e a Noção de Multifuncionalidade da Agricultura. In: CONGRESSO BRASILEIRO DE ECONOMIA, ADMINISTRAÇÃO E SOCIOLOGIA RURAL, Rio Branco, 2008. Anais... Rio Branco: SOBER, 2008. p. 1-18.

8. Valor Econômico (2009) [acesso em 24 ago 2011]. Disponível em: http://www.valor.com.br/ arquivo/608861/uniao-europeia-quer-bem-estar-animalnas-regras-da-omc

9. Brasil. Presidência da República. Lei no 10.831, de 23 de dezembro de 2003. Dispõe sobre a agricultura orgânica e dá outras providências. Diário Oficial da União, Brasilia, 24 dez. 2003. Seção 1, p. 8.

10. Buainain AM, Batalha MO, Alcantara RLC, Chaves GLD. Cadeia produtiva de produtos orgânicos. $1^{\mathrm{a}}$ ed. Brasília: IICA: MAPA/SPA; 2007. v. 1, p. 19.

11. Bastianelli D. A produção de Frangos Diferenciados na França. Mercado, aspectos organizacionais e regulamentares. CONFERÊNCIA APINCO DE CIÊNCIA E TECNOLOGIA AVÍCOLAS, 2001. 2001, Campinas. Anais... Campinas: FACTA, 2001. p. 235-54.

12. Pimenta VP, Sena JOA, Moura LPP, Cunha FAD, Rupp LM, Hisano LK et al. Percepção dos Consumidores quanto aos Produtos Orgânicos na Região de MaringáPR, Brasil. Rev Bras de Agroecologia. 2009;4(2):2903-07.

13. Brasil. Ministério da Agricultura Pecuária e Abastecimento. Legislação para os sistemas orgânicos de produção animal e vegetal. $1^{\mathrm{a}}$ ed. Brasília: MAPA/ACS; 2009.

14. Fundação Mokiti Okada. Microrganismos eficazes na agricultura. $2^{\mathrm{a}}$ ed. Ipeúna: FUNDAÇÃO MOKITI OKADA; 2002. 29 p.

15. Okada M. A outra face da doença: a saúde revelada por Deus. $\sigma^{a}$ ed. Atami, Japão: MOA SHOJI; 1992.

16. Demattê Filho LC, Mendes CMI. Viabilidade técnica e econômica na criação alternativa de frangos. In: CONFERÊNCIA APINCO DE CIÊNCIA E TECNOLOGIA AVÍCOLAS, 2001, Campinas. Anais... Campinas: FACTA, 2001. p. 255-66.

17. Moruzzi Marques PE, Silveira MA. Impactos das novas representações de qualidade alimentar sobre as dinâmicas 
territoriais e a cafeicultura familiar do Sul de Minas Gerais. In: Agricultura Familiar: pesquisa, formação e desenvolvimento. Belém: UFPA. 2009;9:105-20.

18. Farina TMQ, Almeida SF. Consumer Perception on Alternative Poultry. International Food and Agribusiness Management Review. 2003 [acesso em 23 maio 2011]. Disponível em: http://ageconsearch.umn.edu/ bitstream/34533/1/0502fa02.pdf

19. Farina TMQ, Almeida SF. A Percepção dos Consumidores de Frangos "Alternativos". In: CONGRESSO BRASILEIRO DE ECONOMIA E SOCIOLOGIA RURAL, Passo Fundo, 2002. Anais... Passo Fundo: SOBER, 2002. CD-ROM.

20. Farina EMMQ. Competitividade e Coordenação de Sistemas Agroindustriais: Um Ensaio Conceitual. Revista de Gestão e Produção. 1999;6(3):147-61.

21. Kennedy PL, Harrison RW, Piedra MA. Analyzing Agribusiness Competitiveness: Case of the United States Sugar Industry. International Food and Agribusiness Management Review. 1998;1(2):245-57.

22. Instituto Paranaense de Desenvolvimento Econômico e Social. Análise da Competitividade da Cadeia Agroindustrial de Carne de Frango no Estado do Paraná. Curitiba: IPARDES; 2002. 230 p.

23. PORTER ME. THE COMPETITIVE ADVANTAGE OF NATIONS. HARV BUS REV., NEW YORK: FREE PRESS; 1990.

24. Batalha MO. (Coord.). Gestão Agroindustrial: GEPAI Grupo de Estudos e pesquisas agroindustriais. $3^{\mathrm{a}} \mathrm{ed}$. São Paulo: Atlas; 2008.

25. Silva CAB, Batalha MO. Competitividade em Sistemas Agroindustriais: Metodologia e Estudo de Caso. In: II WORKSHOP BRASILEIRO SOBRE GESTÃO DE SISTEMAS AGROALIMENTARES - PENSA/ FEA/USP, 1999, Ribeirão Preto. Anais... Ribeirão Preto: PENSA/FEA/USP, 1999, p. 9-20.

26. Valor Econômico (2011) [acesso em 23 ago 2011. Disponível em: http://www.valor.com.br/ arquivo/866171/apos-dioxina-alemanha-tenta-acalmarpopulacao
27. Pecqueuer B. O desenvolvimento territorial: uma nova abordagem dos processos de desenvolvimento para as economias do Sul. Raízes. 2005; 24(1-2):10-22.

28. Muchnik J, Cañada JS, Salcido TG. Systèmes agroalimentaires localisés: état des recherches et perspectives. Cahiers Agricultures. 2008;17(6):513-19. 